\title{
URBAN IMPERVIOUS SURFACE DETECTION WITH LANDSAT AND FULL POLARIMETRIC ALOS/PALSAR IMAGES
}

\author{
S. Attarchi ${ }^{1, *}$, M. Rahnama ${ }^{2}$ \\ ${ }^{1}$ Dept. of remote sensing and GIS, Faculty of Geography, University of Tehran, Tehran, Iran - satarchi@ut.ac.ir \\ ${ }^{2}$ Dept. of atmospheric surveys research , Atmospheric Science and Meteorological Research Centre, Tehran, Iran- \\ rahnama.m@asmerc.ac.ir
}

Commission VI, WG VI/4

KEY WORDS: Urban impervious surfaces, Full polarimetric SAR, Landsat, Texture, Neural network, Classification

\begin{abstract}
:
Impervious surface detection in urban area is of great importance because impervious surfaces have been recognized as an urbanization index. In other words, an increase of impervious surface extent accounts for urban sprawl. Remote sensing images in optical wavelength proved to be beneficial for urban impervious surfaces detection and mapping. However, the use of optical images is limited in cloud-prone regions. Also, there are some complexities which make it challenging to impervious surface detection especially in urban areas. In recent years, in the light of increasing availability of SAR data, the use of SAR data for urban impervious surface detection is increased as well. In this study the efficiency of full polarimetric L-band images was compared to Landsat images. Furthermore, the role of SAR' texture features was assessed. Results show that the classification accuracy of SAR images cannot overcome the Landsat's classification accuracy. However, SAR texture features provide positive contribution in impervious surface detection in homogeneous urban region.
\end{abstract}

\section{INTRUDUCTION}

Impervious surface detection in urban areas is getting ever more attention because of its relevance to urban sprawl. Optical data proved to be beneficial for urban impervious surfaces detection. However, there is still some complexities in impervious surface detection by optical images in urban environment. Shadows and various impervious surfaces (in terms of size and material) cause the challenges. Also, optical remote sensing is not operational in humid and cloudy weather and fails to detect impervious materials. In recent years, in the light of increasing availability of SAR data, the use of SAR data in urban impervious surface detection increases. The sensitivity of microwave wavelength to roughness and dielectric constant of material lead to an extensive use of SAR images in urban impervious surface detection. In the most researches, the synergy of optic and SAR data have been explored and promise results have been reported.

Impervious surfaces appear diverse in remote sensing images concerning both optic and SAR. The reason of this diversity can be grouped into three main categories. First, impervious surface materials are diverse; cement, asphalt and new building materials. Second, normally urban areas composed of tall buildings, therefore, buildings cast shadow which makes the detection of urban impervious surfaces a complicate task. Third, impervious surfaces consist of a wide range of urban elements with different size and characteristics; building, roads and parking lots act as impervious surface, however, their spatial extents, spectral and polarimetric signatures are various. So, impervious surface detection in urban areas is not a straightforward approach. In the other hand, differentiate between impervious surface and non- impervious surface or different types of impervious surface will not follow the same approach in optic and SAR data. SAR and optical data provide different morphological characteristic of impervious surfaces.

\section{MATERIALS}

\subsection{Datasets}

One Landsat 5 TM Scene acquired on 19 July 2009 and one ALOS-PALSAR (Advanced Land Observing Satellite- Phased Array L-band SAR) full polarimetric image acquired on 23 April 2009 covering Tehran was obtained. The reason for selecting Tehran was its complexity. Tehran is one of the largest metropolitan in the world which encompass different types of impervious surfaces as well as other land cover such as vegetation, water and bare land. Elevation also varies in this city which makes land cover classification based on SAR image a complicated task.

\begin{tabular}{|l|c|c|c|}
\hline Dataset & $\begin{array}{c}\text { Spatial } \\
\text { Resolution } \\
(\mathrm{m})\end{array}$ & Bands & Acquisition \\
\hline Landsat 5 TM & 30 & $1-5,7$ & $\begin{array}{c}\text { 19 July } \\
2009\end{array}$ \\
ALOS/PALSAR & 12.5 & $\begin{array}{c}\text { L (HH, HV, } \\
\text { VH, VV) }\end{array}$ & $\begin{array}{c}23 \text { April } \\
2009\end{array}$ \\
\hline
\end{tabular}

Table 1. Dataset

\footnotetext{
* Corresponding author
} 


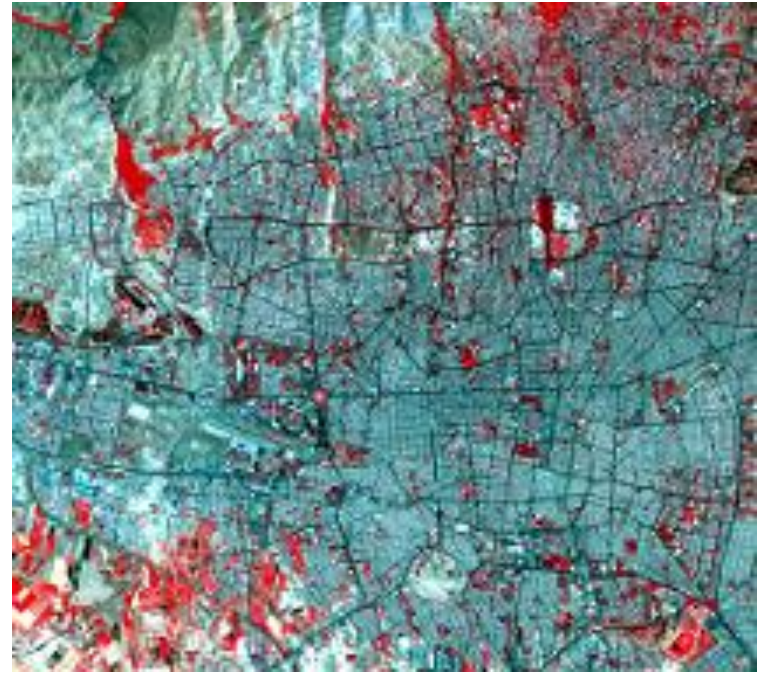

Figure 1. The false colour composition (4R3G2B) image of Landsat 5 TM (mountainous area in the northwest of image was masked)

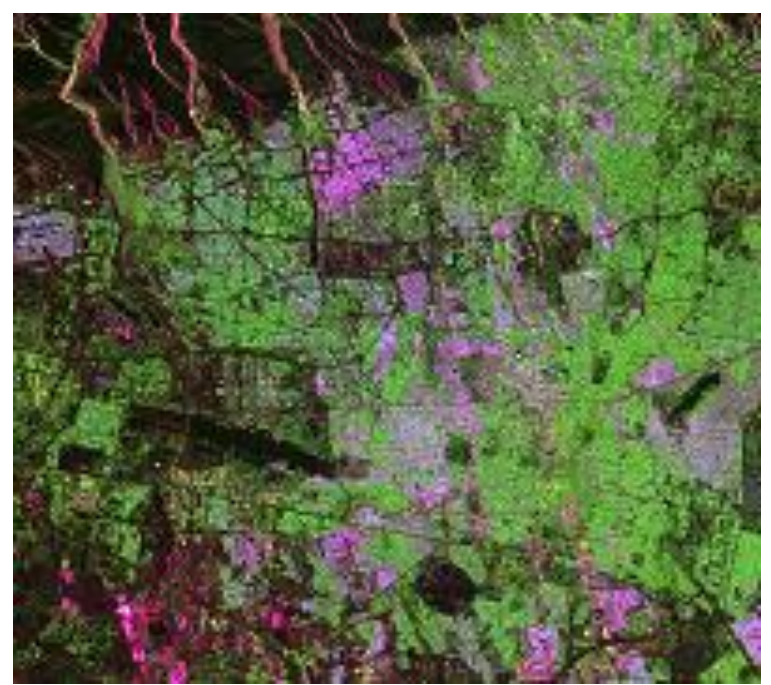

Figure 2. The colour composition (HHR HVG VVB) image of ALOS/PALSAR (mountainous area in the northwest of image affected by layover was masked)

\subsection{Pre-processing}

Both images pre-processed independently prior to classification. Six reflective bands of Landsat (visible and short-wave infrared wavelength) were pre-processed. ATCOR-3 (Atmospheric/Topographic CORrection) for satellite images was used for atmospheric and topographic correction (Richter and Schläpfer, 2005) with the help of Shuttle Radar Topography Mission (SRTM).

Refined Lee filter by window size of $7 * 7$ was performed on ALOS/PALSAR scene to compensate speckle effect. The selection of filter type and its window size was based on suppression and mean preservation index (SMPI) (Shamsoddini et al., 2010). Then intensity values converted into radar backscattering coefficients (Sigma nought, dB) (Shimada et al., 2009).

$$
\sigma^{\circ}=10 \times \log _{10}(D N)^{2}+C F
$$

where $\quad \sigma^{\circ}=$ radar backscattering coefficient

$\mathrm{DN}=$ pixel value

$\mathrm{CF}=$ calibration factor which is -60 for full polarimetric data

Because of the relief effect in the scene, radiometric terrain correction was done. Topographic normalized radar backscattering coefficient (Gamma nought) which consider local incident angle was computed based on sigma nought and local incident angle (Ulander, 1996).

$\nu^{\circ}=\sigma^{\circ} A_{\text {flat }} / A_{\text {slope }}\left(\cos \theta_{\text {ref }} / \cos \theta_{\text {loc }}\right)^{n}$

Where $\gamma^{\circ}=$ topographic normalized radar backscattering coefficient

$\sigma^{\circ}=$ radar backscattering coefficient

$\mathrm{A}_{\text {flat }}=$ PALSAR pixel size for a theoretical flat terrain

$A_{\text {slope }}=$ True local PALSAR pixel size for the terrain with elevation changes

$\theta_{\text {ref }}=$ radar incidence angle at the image center

$\theta_{\text {loc }}=$ local incidence angle

The exponent $\mathrm{n}$ is the optical canopy depth and it changes between 0 and 1. It is a site-specific factor and practically it is difficult to calculate, it is set to 1 according to Lucas et al. (2010).

In order to extract textural features from polarized bands, gray level co-occurrence matrix (GLCM) was implemented with a window size of $3 * 3$ (Haralick and Shanmugam, 1973). It was reported that the inclusion of texture features has positive effect on the delineation of impervious surfaces (Dekker, 2003; Puissant et al., 2005; Voisin et al., 2013). Layer stacks of each group of dataset (Landsat and ALOS/PALSAR) were separately generated in order to combine multiple images into a single image.

\section{METHODOLOGY}

First, four distinct land cover classes were identified in the image; Vegetation (mainly natural or man-made parks), water body (artificial lake or water pool), bare land (land with no surface cover) and impervious surfaces (residential areas, streets and high ways, buildings shadow and parking places).

For land cover classification, neural network was employed. Neural network is a nonparametric classifier which easily adapt to various input data types and structures. It also supports fuzzy output values and is capable of estimating the non-linear relationship between the input data and desired outputs. In this study, the setting parameters were assigned based on experimental results. The activation function was set to logistic and training iterations were fixed on 1000 .

For each land cover classes, ca. 500 pixels were selected as representative land cover in a selected scene. Nearly 300 pixels of each class served as training samples. The selection of these pixels was done with the help of visual interpretation of Google Earth image. The high spatial resolution image near acquisition time of Landsat and ALOS image (2009) was obtained from Google Earth. The separability analysis among training samples was performed based on Jeffries-Matusita index. The separability index shows how well the training sample pairs are statistically separable. The index values range from 0 to 2 . Values greater than 1.8 shows good separability between a pair of training samples. When training samples of two classes have 
the separability index less than 1 , it is recommended to combine them into a single class. The separability index values changes from 1 to 1.8 , should be improved either by selecting new samples or editing the existing ones.

SAR and optic data were co-registered manually. The registration error was acceptable (less than 0.5 pixel). For classification accuracy assessment, independent samples are needed. For that, the remaining samples of each land cover class (ca. 200 pixels) served as validating samples. Then confusion matrices were developed based on comparison between classification results and independent validation samples. The producer and user accuracies of each land cover classes were computed from confusion matrices (Jensen and Lulla, 1987).

\section{RESULTS}

\subsection{Assessment of Separability Index}

Training samples on Landsat image have high separability indices, showing an acceptable separation among land cover classes which guarantee good differentiation among impervious surfaces and other land cover classes (Table 2). Therefore, classification was done based on these training samples.

\begin{tabular}{|l|c|c|c|c|}
\hline & Impervious & Vegetation & Water & Bare l. \\
\hline Impervious & - & 1.99 & 1.99 & 1.88 \\
Vegetation & & - & 1.99 & 1.99 \\
Water & & & - & 2.00 \\
Bare land & & & & - \\
\hline
\end{tabular}

Table 2. Separability index values for different pairs of land cover classes on Landsat image

\begin{tabular}{|l|c|c|c|c|}
\hline & Impervious & Vegetation & Water & Bare 1. \\
\hline Impervious & - & 1.20 & 1.47 & 1.67 \\
Vegetation & & - & 1.65 & 1.26 \\
Water & & & - & 1.8 \\
Bare land & & & & - \\
\hline
\end{tabular}

Table 3. Separability index for different pairs of land cover classes on full polarimetric ALOS/PALSAR image

However, separability indices values between pairs of classes is not high on full polarimetric SAR data. This is also true for impervious surfaces detection from other land cover classes (Table 3). Almost all training sample pairs have separability index less than threshold (i.e. 1.8). Therefore, it is decided to merge other land cover classes (except impervious surfaces) into one class and reselect training samples. Instead of 4 land cover classes detected on Landsat, ALOS/PALSAR was classified into two classes; impervious surfaces and nonimpervious surfaces.

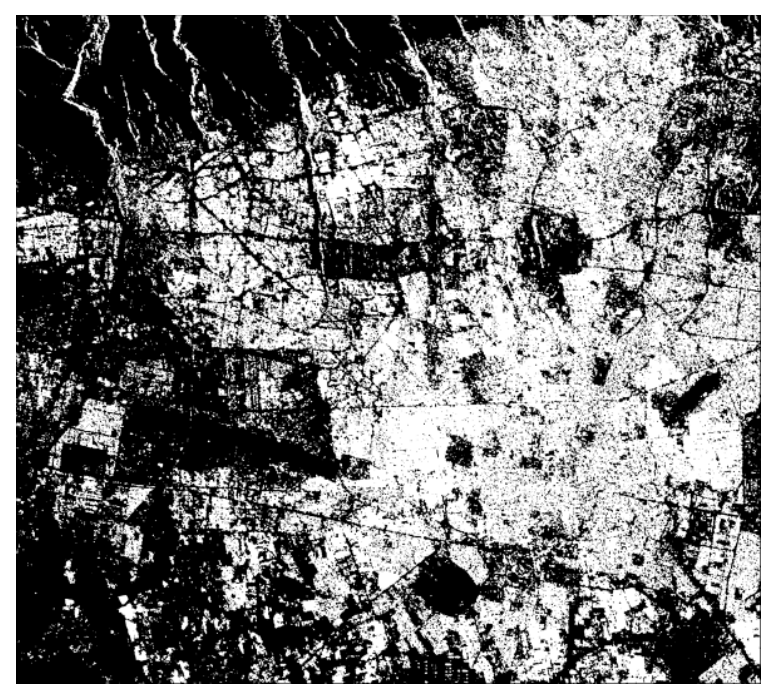

Figure 3. Classification of polarimetric bands of

ALOS/PALSAR image (White: impervious surfaces, Black: non-impervious surfaces)

\subsection{Assessment of the Classification Accuracy}

Based on training samples, Landsat and ALOS/PALSAR datasets were independently classified by neural network classifier (Table 4 and Table 5). As mentioned in previous section (4.1), four distinct land cover classes have been considered for Landsat images. Nevertheless, based on separability index's assessment, only two classes were considered for ALOS/PALSAR classification (Figure 3).

\begin{tabular}{|l|c|c|}
\hline Land cover class & \multicolumn{2}{|c|}{ Accuracy $(\%)$} \\
\hline & Producer & User \\
Impervious & 98.0 & 98.0 \\
Vegetation & 99.8 & 99.7 \\
Water & 100 & 100 \\
Bare land & 91.9 & 100 \\
\hline \multicolumn{2}{|l|}{ Overall accuracy $=98.42 \%$} \\
\hline
\end{tabular}

Table 4. Producer and user accuracy (Landsat 5 TM)

\begin{tabular}{|l|c|c|}
\hline Land cover class & \multicolumn{2}{|c|}{ Accuracy (\%) } \\
\hline & Producer & User \\
Impervious & 80.9 & 78.3 \\
Non-impervious & 93.3 & 93.7 \\
\hline \multicolumn{2}{|l|}{ Overall accuracy $=84.13 \%$} \\
\hline
\end{tabular}

Table 5. Producer and user accuracy (ALOS/PALSAR full polarimetric) 


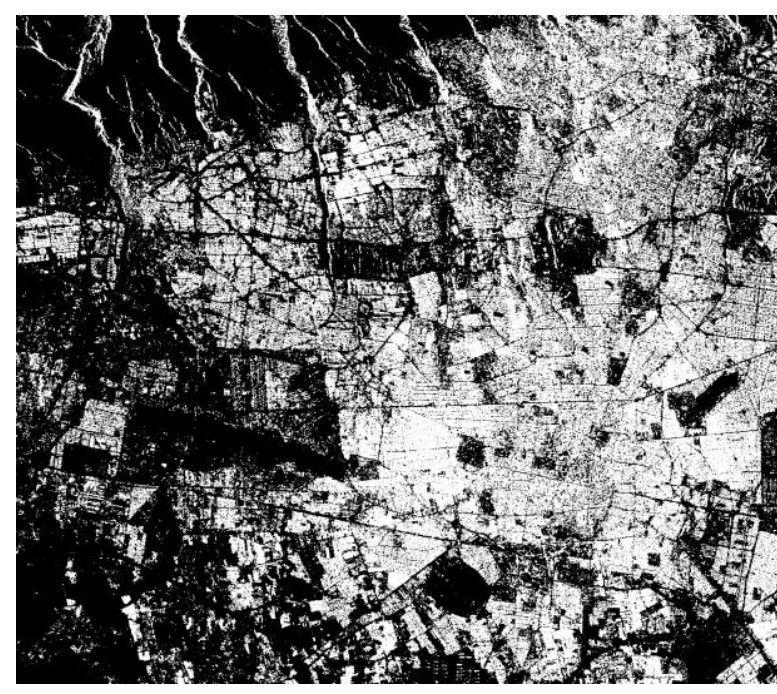

Figure 4. Classification of polarimetric bands and texture features of ALOS/PALSAR image (White: impervious surfaces, Black: non-impervious surfaces)

Since the classification accuracy of PolSAR image did not reached the accuracy of Landsat image, in the next step, the contribution of textures of polarized band in classification overall accuracy was also evaluated (Figure 4). The inclusion of texture improves the classification accuracy, and it is very close to the Landsat TM classification result (Table 6).

\begin{tabular}{|l|c|c|}
\hline Land cover class & \multicolumn{2}{|c|}{ Accuracy (\%) } \\
\hline Impervious & Producer & User \\
Non-impervious & 82.2 & 96.4 \\
\hline \multicolumn{2}{|l|}{ Overall accuracy $=95.86 \%$} & 84.8 \\
\hline
\end{tabular}

Table 6. Producer and user accuracy (ALOS/PALSAR full polarimetric + GLCM texture)

\section{DISCUSSION AND CONCLUSION}

The single use of Polarized L-band SAR could not detect impervious surfaces from diverse land cover classes efficiently. However, the integration of texture of polarimetric bands at $\mathrm{L}$ band wavelength showed positive contribution in separating impervious surfaces from non-impervious surfaces in complex urban area. The classification accuracy obtained by inclusion of SAR texture features and polarimetric L-band shows that Lband SAR can be used for urban impervious surface detection. In cloud-prone area, weather situation limits availability of optical images with good quality. In some area no optical image with limited cloud cover may be found for several successive months. This is also true for the long term archive of Landsat images. Despite the fact that Landsat has the 16 days' revisit time, in many regions, no Landsat images are available during rainy months. Therefore, it is important that the efficiency of SAR images in impervious surface mapping be examined. The findings of this research prove that when no optical image at medium resolution is available full polarimetric L-band SAR images can be used alternatively. Polarimetric bands and their driven texture features are capable in detection of impervious surfaces in heterogonous urban area with high relief.

\section{ACKNOWLEDGEMENTS (OPTIONAL)}

The authors are grateful to European Space Agency, for making available the ALOS/PALSAR PLR images.

\section{REFERENCES}

Arnold Jr, C. L., \& Gibbons, C. J., 1996. Impervious surface coverage: the emergence of a key environmental indicator. Journal of the American Planning Association, 62(2), 243-258.

Brabec, E., Schulte, S., \& Richards, P. L., 2002. Impervious surfaces and water quality: a review of current literature and its implications for watershed planning. Journal of planning literature, 16(4), 499-514.

Cloude, S. R., \& Pottier, E., 1997. An entropy based classification scheme for land applications of polarimetric SAR. IEEE transactions on geoscience and remote sensing, 35(1), 6878.

Dekker, R. J.,2003. Texture analysis and classification of ERS SAR images for map updating of urban areas in the Netherlands. IEEE Transactions on Geoscience and Remote Sensing, 41(9), 1950-1958.

Espey Jr, W. H., Morgan, C. W., \& Masch, F. D. , 1966. Study of some effects of urbanization on storm runoff from a small watershed. Texas Water Development Board.

Ferro-Famil, L., Pottier, E., \& Lee, J. S. , 2001. Unsupervised classification of multifrequency and fully polarimetric SAR images based on the H/A/Alpha-Wishart classifier. IEEE Transactions on Geoscience and Remote Sensing, 39(11), 23322342.

Gamba, P., \& Aldrighi, M., 2012. SAR data classification of urban areas by means of segmentation techniques and ancillary optical data. IEEE Journal of Selected Topics in Applied Earth Observations and Remote Sensing, 5(4), 1140-1148.

Haralick, R. M., \& Shanmugam, K., 1973. Textural features for image classification. IEEE Transactions on systems, man, and cybernetics, (6), 610-621.

Jensen, J.R. and Lulla, K., 1987. Introductory digital image processing: a remote sensing perspective.

Lucas, R., Armston, J., Fairfax, R., Fensham, R., Accad, A., Carreiras, J., Kelley, J., Bunting, P., Clewley, D., Bray, S. and Metcalfe, D., 2010. An evaluation of the ALOS PALSAR Lband backscatter-Above ground biomass relationship Queensland, Australia: Impacts of surface moisture condition and vegetation structure. IEEE Journal of Selected Topics in Applied Earth Observations and Remote Sensing, 3(4), pp.576593.

Puissant, A., Hirsch, J., \& Weber, C, 2005. The utility of texture analysis to improve per-pixel classification for high to very high spatial resolution imagery. International Journal of Remote Sensing, 26(4), 733-745.

Richter, R. and Schläpfer, D., 2005. Atmospheric/topographic correction for satellite imagery. DLR report DLR-IB, 565. 
Schueler, T.,1994. The importance of imperviousness. Watershed protection techniques, 1(3), 100-101.

Shamsoddini, A., Trinder, J.C., Wagner, W. and Székely, B., 2010. Image texture preservation in speckle noise suppression. na.

Shimada, M., Isoguchi, O., Tadono, T. and Isono, K., 2009.

PALSAR radiometric and geometric calibration. IEEE

Transactions on Geoscience and Remote Sensing, 47(12), pp.3915-3932.

Ulander, L.M., 1996. Radiometric slope correction of syntheticaperture radar images. IEEE Transactions on Geoscience and Remote Sensing, 34(5), pp.1115-1122.

Voisin, A., Krylov, V. A., Moser, G., Serpico, S. B., \& Zerubia, J., 2013. Classification of very high resolution SAR images of urban areas using copulas and texture in a hierarchical Markov random field model. IEEE Geoscience and Remote Sensing Letters, 10(1), 96-100.

Wei, C., \& Blaschke, T., 2018. Pixel-Wise vs. Object-Based Impervious Surface Analysis from Remote Sensing: Correlations with Land Surface Temperature and Population Density. Urban Science, 2(1), 2.

Weng, Q., Lu, D., \& Liang, B., 2006. Urban surface biophysical descriptors and land surface temperature variations. Photogrammetric Engineering \& Remote Sensing, 72(11), $1275-1286$.

Yang, F., Matsushita, B., \& Fukushima, T., 2010. A prescreened and normalized multiple endmember spectral mixture analysis for mapping impervious surface area in Lake Kasumigaura Basin, Japan. ISPRS Journal of Photogrammetry and Remote Sensing, 65(5), 479-490.

Yuan, F., \& Bauer, M. E., 2007. Comparison of impervious surface area and normalized difference vegetation index as indicators of surface urban heat island effects in Landsat imagery. Remote Sensing of environment, 106(3), 375-386. 